\title{
Financing Decisions Analysis of E-commerce Supply Chain Finance for Fresh Agricultural Products in China
}

\author{
Ning Xian* \\ Decision and Risk Analysis, University of Southampton, Shanghai, 200070, China
}

\begin{tabular}{l} 
ARTICLE INFO \\
Article history \\
Received: 19 April 2021 \\
Revised: 26 April 2021 \\
Accepted: 20 October 2021 \\
Published Online: 30 October 2021 \\
\hline
\end{tabular}

Keywords:

E-commerce supply chain finance

SCF solutions

SMEs supply chain financing decision analysis

Supply chain management

Fresh agricultural products

\begin{abstract}
The supply chain finance (SCF) solutions are becoming increasingly diversified with the continuous perfection of the economic system. However, financing for small and medium sized enterprises (SMEs) is still a difficult issue waiting to be solved by enterprises and the government in China. SCF solutions based on e-commerce platforms have developed rapidly in China that provide an alternative for SMEs when few studies have been conducted on e-commerce SCF solutions which focus on fresh agricultural products. Therefore, this research focuses on the SCF solutions applicable to e-commerce enterprises of fresh agricultural products.
\end{abstract}

\section{Introduction}

Small and medium sized enterprises (SMEs) have long been an important force in the development of the national economy, which provide lots of employment opportunities for society. The financing solutions of SMEs are becoming increasingly diversified with the continuous maturity and perfection of the market economy. These enterprises not only adopt the traditional financing model from commercial banks, but also use other innovative financing solutions. However, financing for SMEs is still a difficult issue in China. According to a survey by the Shanghai Statistics Bureau, only $27.3 \%$ of SMEs have access to bank loans when the probability of obtaining financing from other channels is even lower ${ }^{[1]}$.

In recent years, China's e-commerce market has been growing rapidly and it ranked first in the world, followed by the United States, the United Kingdom, Japan, Germany, France, South Korea, Canada, Russia and Brazil ${ }^{[2]}$. In 2017, online trading volume in China was RMB 7,715 billion, accounting for $19.6 \%$ of the total volume ${ }^{[3]}$. By 2018, the number of users in China's e-commerce industry reached 330 million, with an increase of $46.66 \%$ ${ }^{[4]}$. E-commerce platforms transfer traditional offline retail business to the Internet platforms, effectively decreasing the information asymmetry between buyers and sellers and expanding the transaction scale of e-commerce platforms. Therefore, the supply chain finance (SCF) model based on e-commerce platforms emerged under the joint effect of the financing difficulties of SMEs and the rapid development of the e-commerce market. In the

*Corresponding Author:

Ning Xian,

Decision and Risk Analysis, University of Southampton, Shanghai, 200070, China;

Email:qixi177@gmail.com 
e-commerce supply chain finance platforms, participants in the business process can effectively work with large amounts of data and control transactions ${ }^{[2]}$. Compared to traditional offline financing, it not only reduces the information asymmetry and transaction costs in the financing process, but also accelerates the speed of capital turnover and operational efficiency of the supply chain.

The e-commerce market of fresh agricultural products is in a period of rapid development. Since 2016, fresh agricultural products e-commerce has maintained a high growth rate of over $40 \%$ according to the monitoring data of e-commerce Research Center ${ }^{[4]}$. However, most fresh e-commerce enterprises in the rapid growth of the scale are in a loss-making state ${ }^{[5]}$. The damage rate of fresh agricultural products is very high due to the characteristics of perishable and not easy to keep fresh. E-commerce companies often bear the financial burden of the damage caused by the destruction of large quantities of agricultural products. Therefore, it is necessary to address the problems related to the e-commerce supply chain of fresh agricultural products. The fresh agricultural products supply chain is the research target in this research.

Supply chain finance based on e-commerce platforms has different financing solutions. The upstream and downstream enterprises in the supply chain have to deal with various risks under different financing solutions such as accounts receivable financing and purchase order financing. Also, some mathematical models such as VaR and CVaR are often used to quantitatively analyze financing strategies and measure risks in e-commerce supply chain finance. Value at risk $(\mathrm{VaR})$ determines the extent of potential losses in an institutional portfolio. It is applied to control risk exposure as the statistic measures the level of financial risk by calculating the maximum loss expected for a given degree of confidence on an investment over a specific time period. Conditional Value at Risk (CVaR) quantifies the amount of tail risk on the portfolio, which is derived by taking an average of the losses beyond the VaR cutoff point.

\section{Brief Statement of E-commerce Fresh Agricultural Products SCF}

In recent years, with the improvement of people's living standards, consumers increasingly expect products to be fresh and secure. In China, $25 \%$ to $35 \%$ of fresh products are wasted ${ }^{[6]}$. In the United States, more than $40 \%$ of perishable products are wasted every year ${ }^{[7]}$. In developed Western economies, grocery retailers lose up to $15 \%$ due to perishability ${ }^{[8]}$. Thus, it is important for retailers to keep products fresh. Fresh agricultural products such as fruit, vegetables and meat are highly perishable, and retailers may be under heavy pressure to prevent fresh products from rotting. In this case, scholars should pay more attention to fresh agricultural products SCF based on e-commerce enterprises so as to reduce the financial pressure and loss for retailers. However, few studies have been conducted on e-commerce SCF which focus on fresh agricultural products. Therefore, this study will focus on the e-commerce of fresh agricultural products SCF.

\section{E-commerce SCF Solutions for Fresh Agricultural Products}

\subsection{Background and Objectives}

Small and medium-sized enterprises (SMEs) play a significant role in economic development and have a positive effect on overall growth enterprises, real GDP growth, job creation, and poverty reduction. However, the development of the national economy has been restricted, one of the reasons being the financing difficulties of small and medium-sized enterprises. Many SMEs are not able to obtain investment because of their small scale and low credit rating. Thus, the issue of how to effectively and efficiently finance small-medium-sized enterprises has aroused widespread concern among academia and practitioners. In recent years, supply chain finance (SCF) has been rapidly developed as a new type of financing model in China. At the same time, SCF based on e-commerce has broad prospects; more and more enterprises have begun to adopt online financing, with the rise of internet finance and e-commerce. E-commerce enterprises integrate logistics, information flow, and capital flow, make them more transparent through the development of their own logistics platforms, and thus get involved in the area of e-commerce SCF. With the continuous development of e-commerce supply chain finance, SMEs become more able to obtain the funds through e-commerce platforms. However, the consequences of e-commerce SCF may be negative. Although e-commerce SCF has many merits, such as high efficiency, timeliness, and low cost, there are some new problems in risk management due to more complex virtual network environments and participants. Among the general SCF solutions, the most widely used are accounts receivable financing, purchase order financing, and reverse factoring ${ }^{[9]}$. SCF solutions can be divided into traditional and innovative financing solutions by certain characteristics. E-commerce SCF solutions, as one of the innovations, are also applicable to traditional SCF solutions. 


\subsection{General SCF Solutions in E-commerce Platforms}

\subsubsection{Accounts receivable financing}

In this section, this study focuses on several traditional and e-commerce SCF models. The first is the accounts receivable financing model. As accounts receivable become effective collateral, the financing of accounts receivable is more important in the international market. Accounts receivable are used as collateral for the company to obtain loans ${ }^{[10]}$. As one of the largest and most liquid assets of an enterprise, they are critical in facilitating business transactions. The accounts receivable financing mode in the supply chain introduces core enterprises that are related to SMEs. SMEs obtain loans from commercial banks by using accounts receivable as a mortgage ${ }^{[11]}$. Accounts receivable financing in e-commerce SCF is a financial mode in which the upstream enterprises transfer the accounts receivable rights of the downstream enterprises to the e-commerce financial department as a pledge to obtain credit. From the perspective of core enterprise, e-commerce enterprises not only provide loan guarantees for SMEs but also mix the entire supply chain through the flow of funds, benefiting all enterprises in the supply chain. From the perspective of financing enterprises, the accounts receivable financing mode in e-commerce SCF does not need the credit granted by commercial banks to obtain funds, which reduces the financing cost compared with the traditional accounts receivable financing mode. On the other hand, this mode improves the speed of the commodity sales revenue of downstream enterprises, thus speeding up capital turnover.

\subsubsection{Purchase order financing}

Purchase order financing stems from packaging loans in international trade and extends to the marketing trade chain throughout the supply chain ${ }^{[12]}$. It is a type of supplier financing in which the bank assesses the chance of the supplier successfully delivering the order, based on the value of the purchase order issued by the reputable buyer, and provides loans to the supplier ${ }^{[13]}$. The target customers of this model service are the upstream financing enterprises with fast command execution and strong credit. In the purchase order financing model, suppliers are able to use the financing of purchase orders to purchase products; this is helpful in dealing with the problem of capital constraints in upstream enterprises and greatly enhances the ability of suppliers to process funds. Besides, this model greatly shortens the trading cycle and improves the efficiency of the entire supply chain so that the supply chain operation is more stable ${ }^{[14]}$.

\subsubsection{Factoring and reverse factoring}

In factoring, the company sells its creditworthy accounts receivable at a discount, which is usually equal to interest plus service fees, and obtains immediate cash ${ }^{[15]}$. Factoring has the following advantages. Firstly, since the credit provided by the lender is strongly related to the value of the supplier's accounts receivable and not to the supplier's overall reputation, factoring enables high-risk suppliers to transfer their credit risk to high-quality buyers ${ }^{[15]}$. Then, the financial sector does not have a pledge guarantee requirement for financing enterprises, which can obtain funds in advance by selling accounts receivable claims, thus speeding up the turnover of funds. Reverse factoring, as the most popular tool in different supply chain financing strategies initiated by large companies with high quality credit ratings, is a mechanism to alleviate supplier financing problems ${ }^{[16]}$. In the supply chain based on e-commerce platforms, this model relates to the three-party scheme between the supplier, the buyer, and the institution that provides financing, such as a bank or an e-commerce enterprise. The reverse factoring model can also transfer financial risk from the supplier to the buyer, like the factoring model. In addition, reverse factoring can bring direct benefits to all participants throughout the supply chain ${ }^{[17]}$.

\subsubsection{E-commerce SCF solutions for fresh agricultural products}

Consumers can directly access fresh agricultural products through e-commerce platforms so as to expand the circulation of fresh agricultural products. The intervention of e-commerce platforms helps fresh agricultural products break the geographical restrictions of tangible markets and balance the agricultural production and market demand in China ${ }^{[18]}$. In view of this, it is also meaningful to analyze the financing solutions of fresh agricultural product SCF based on e-commerce platforms in China. All four financing models involved in this Section can be applied to fresh agricultural products in e-commerce supply chain finance, and the accounts receivable financing model will be introduced at length. The operation process of accounts receivable financing is as follows:

(1) The upstream enterprise (supplier) in the supply chain signs the procurement contract with the e-commerce enterprise, which stipulates that the supplier shall provide the products to the e-commerce enterprises and the e-commerce enterprises shall pay within the agreed account period after receiving the products.

(2) E-commerce enterprises check and upload accounts 
payable information on the e-commerce platform, suppliers check accounts online and supplement invoice information, and then they can apply for financing selectively.

(3) Financial institutions (banks) conduct online batch approval and release funds to supplier enterprises, based on their judgment on the authenticity of the transaction and credit rating of borrowing enterprises, then evaluate the value of accounts receivable and register the pledge of accounts receivable.

(4) Suppliers get accounts receivable in advance, and e-commerce enterprises pay back to the bank on the due date.

\section{Risk Control of SCF Solutions for Fresh Agricultural Products}

\subsection{Inventory Financing}

The risk in the process of inventory financing is mainly reflected in the realisation risk of collateral when the borrower is unable to repay the principal and interest at maturity. When the collateral is difficult to realize or cannot cover the principal and interest that the borrower should repay after the collateral is realized, the e-commerce supply chain platform may suffer losses. Therefore, the following key points need to be noticed in inventory financing risk control. First, regular review of inventory control and shelf life is required. Second, it is necessary to set the pledge rate and loan interest rate according to the borrower's credit status and the difficulty of the realization of pledges. Third, the inventory value should be updated in real time, according to the changes in the market value of the inventory. The borrower shall be required to replenish the collateral or prepay the loan immediately when the inventory falls in value.

\subsection{Purchase Order Financing}

Since purchase order financing is carried out in the form of a credit loan, the loan quota is set relatively low. If the loan interest rate is too high, this model will be replaced by other financial products to a certain extent. Borrowers may default if the price of trading products falls sharply in purchase order financing. Therefore, the key points of risk control for purchase order financing are as follows. First, analyze and evaluate the credit qualification of enterprises by collecting all kinds of data information, so as to determine the appropriate loan interest rate. Second, the supply chain finance platform should adjust the deposit ratio if the price of trading drops significantly during the financing period: for example, the deposit rate changes from $20 \%$ to $30 \%$.

\subsection{Accounts Receivable Financing}

The accounts receivable financing model is complicated in SMEs due to the principal-agent relationship between e-commerce enterprises, suppliers, and retailers ${ }^{[19]}$. So the risks in the financing process also have the characteristics of being dynamic and complex. The retailer may be at risk of default when trading products are subject to large price reductions, which cause the supplier to lose the source of the repayment. Therefore, in the accounts receivable financing model, available data information and industry information should be acknowledged to determine whether retailers can pay their bills on time. In addition, market risks, legal risks, macro system risks, and other risks also exist in the accounts receivable financing model ${ }^{[19]}$.

\section{Conclusions}

Since few scholars have analyzed the e-commerce SCF solutions of fresh agricultural products and there exist some problems which need to be solved in the financing solutions and risk control, this research conducts qualitative research on financing models and risk control. This study introduces general financing solutions applicable to different types of supply chains and explores the advantages of accounts receivable financing, purchase order financing, factoring, and reverse factoring compared to traditional financing solutions. This study also suggests that accounts receivable financing as a type of representative financing solution can be applied to the fresh agricultural products e-commerce industry. Moreover, the financing progress of accounts receivable financing for e-commerce supply chain is explored.

\section{References}

[1] Peng, F., and Bi, X., 2010. Study on the development of e-commerce and SMEs' supply chain financing in China. In 2010 International Conference on E-Business and E-Government, pp. 3435-3438. IEEE.

[2] Lahkani, M., Wang, S., Urbański, M. and Egorova, M., 2020. Sustainable B2B E-Commerce and Blockchain-Based Supply Chain Finance. Sustainability, 12(10), pp.3968.

[3] Chen, X., Liu, C., Li, S., 2019a. The role of supply chain finance in improving the competitive advantage of online retailing enterprises. Electronic Commerce Research and Applications, 33, p.100821.

[4] Fu, L., 2020. Research on S2B2C E-commerce Model of Fresh Agricultural Products in the Field of Social E-commerce. IOP Conference Series: Materials Science and Engineering, 740, p.012155.

[5] Han, D. and Jing, M., 2018. Study on Consumers' 
Multiple Levels Cognitive Behavior to Purchase Fresh Agricultural Products Online. IOP Conference Series: Earth and Environmental Science, 186, p.012015.

[6] Yang, L., Tang, R. and Chen, K., 2017. Call, put and bidirectional option contracts in agricultural supply chains with sales effort. Applied Mathematical Modelling, 47, pp.1-16.

[7] Chen, J., Dong, M. and Xu, L., 2018. A perishable product shipment consolidation model considering freshness-keeping effort. Transportation Research Part E: Logistics and Transportation Review, 115, pp.56-86.

[8] Ferguson, M., Ketzenberg, M.E., 2006. Information sharing to improve retail product freshness of perishables. Product. Operat. Manage., 15 (1) (2006), pp.57-73.

[9] Marak, Z. R., and Pillai, D., 2018. Factors, outcome, and the solutions of supply chain finance: Review and the future directions. Journal of Risk and Financial Management, 12(1), pp.1-23.

[10] Freixas, X., 1993. Short term credit versus account receivable financing. NBER, pp. 15-31.

[11] Liao, Z, Zhao, X., and Feng, Z., 2015. Analysis on supply chain finance accounts receivable financing mode game. International Conference on Education, Management, Commerce and Society (EMCS-15). Atlantis Press.

[12] Li, Y., 2008. Process-focused risk analysis and management of purchase-order financing under logistic financing innovation. In 2008 4th International Conference on Wireless Communications, Networking and Mobile Computing, pp.1-5. IEEE.
[13] Babich, V. and Kouvelis, P., 2018. Introduction to the Special Issue on Research at the Interface of Finance, Operations, and Risk Management (iFORM): Recent Contributions and Future Directions. Manufacturing \& Service Operations Management, 20(1), pp.1-18.

[14] Jiang, L., and Su Y., 2016. Research on Order Financing System Dynamics in the Chain Finance Model. Cross-Cultural Communication, 12(8), pp. 25-30.

[15] Klapper, L., 2006. The role of factoring for financing small and medium enterprises. Journal of Banking \& Finance, 30(11), pp.3111-3130.

[16] Lekkakos, S.D., Serrano, A., and Ellinger, A., 2016. Supply chain finance for small and medium sized enterprises: the case of reverse factoring. International Journal of Physical Distribution \& Logistics Management.

[17] Lacono, U.D., Reindrop, M., and Dellaert N., 2015. Market adoption of reverse factoring. Market adoption of reverse factoring. International Journal of Physical Distribution \& Logistics Management.

[18] Han, D. and Jing, M., 2018. Study on Consumers' Multiple Levels Cognitive Behavior to Purchase Fresh Agricultural Products Online. IOP Conference Series: Earth and Environmental Science, 186, p.012015.

[19] Deng, A. and Du, 2017. Research of Risk Identify of Accounts Receivable Financing Based on System Dynamics. Word Journal of Research and Review, 5(3), pp.43-38. 